\title{
Influencing Factors of Accounting Practitioners' Acceptance of Mobile Learning
}

\author{
https://doi.org/10.3991/ijet.v17i01.28465 \\ Guang Cheng ${ }^{1,2(\bowtie)}$, Yige Shao ${ }^{1,3}$ \\ ${ }^{1}$ Dongbei University of Finance and Economics, Dalian, China \\ ${ }^{2}$ Henan University of Engineering, Zhengzhou, China \\ ${ }^{3}$ University of California-Irvine, Irvine, U.S. \\ chengguang@haue.edu.cn
}

\begin{abstract}
Due to the lack of teaching purpose and planning of mobile learning platform, fragmented learning time, and strong blindness of accounting practitioners, accounting practitioners have insufficient internal motivation to accept mobile learning. Based on the unified theory of acceptance and use of technology (UTAUT model), subject factor (absorptive capacity) and object factor (organizational commitment) of accounting practitioners to accept mobile learning were included, and influencing factors of accounting practitioners to accept mobile learning were empirically explored. The results show that overall Cronbach's a coefficient of the questionnaire is 0.794 , indicating that reliability of the questionnaire is good. KMO value is 0.860 , which is greater than 0.8 , indicating very good data validity. Expected performance, effort performance, social impact and absorptive capacity positively affect accounting practitioners' willingness to use mobile learning. Facilitation conditions and organizational commitments do not affect accounting practitioners' willingness to use mobile learning. Results of single-factor analysis of variance show that interactive friendliness of mobile learning platform has a significant difference in accounting practitioners' willingness to use mobile learning. Results of this study have reference value for understanding how new educational technologies affect people in related industries to receive continuing education and to promote lifelong learning by adopting ubiquitous learning.
\end{abstract}

Keywords - the UTAUT model, accounting practitioners, mobile learning, influencing factors

\section{Introduction}

Under the background of "Internet +", the popularization of mobile Internet and extensive connectivity of mobile intelligent terminal devices provide a lot of opportunities for mobile learning. As a new technology for education, mobile learning has greatly improved portability of people's access to resources, created a new learning environment and provided rich learning experience for learners. In China, some universities have expanded course content from online learning platforms to mobile 
learning platforms. Effective implementation of any information technology or information system depends on user acceptance. In recent years, wireless communication technology is mature year by year, and wireless communication network can cover more areas, and allow more people to learn anytime and anywhere. Especially with fast development of smart phones, the lower price can let people use more free time to find their "fragmented" study interest and can raise their learning enthusiasm and learning efficiency. As a learning method relying on mobile carriers and wireless transmission technology, mobile learning ultimately affects learners and their learning interest, demand, use degree and learning effect are also affected by learners' acceptance factors of the technology to a certain extent.

With the continuous advancement and development of information technology, Internet enterprises are developing towards a new direction of artificial intelligence. The traditional accounting industry is facing great impact. With the change and development of artificial intelligence technology, electronic information technology is gradually refined and improved. More enterprises use ERP system and directly apply related software to complete accounting, compiling statements, submitting tax returns and other accounting-related work. With the popularization of artificial intelligence technology, many basic accounting positions will be eliminated, and many new positions will be created by integration of accounting and other industries. In the context of application of artificial intelligence, accounting practitioners should gradually transform to management accounting, and individuals need to learn more knowledge and skills to become composite accounting talents. Only by actively learning the latest technology such as computer technology and artificial intelligence technology, can accounting practitioners effectively apply it to improve work performance. However, at present, many mobile learning platforms lack demand analysis for accounting practitioners and do not form a systematic learning system for them to improve their accounting skills. As a result, learning time is fragmented and learning process is discontinuous, and learning effect is greatly reduced, making them gradually reduce interest in mobile learning. Therefore, based on the UTAUT model, it is of great practical significance to analyze influencing factors of accounting practitioners' acceptance of mobile learning.

\section{Theoretical basis and research hypothesis}

\subsection{Theoretical basis}

Many scholars discussed influencing factors of information technology and information system use from perspective of technology acceptance, and they had put forward influencing factor models. The UTAUT model is short for unified theory of acceptance and use of technology. The purpose is to explain the user's intention to use the information system and subsequent behavior. This model was developed by integrating the construction of eight models that explained usage behavior of information systems in the early stage [1], including theory of rational action (TRA), technology acceptance model (TAM), theory of planned behavior (TPB), technology acceptance 
model and theory of planned behavior (TAM-TPB), model of personal computer usage (MPCU), motivation model (MM), social cognitive theory (SCT) and innovation diffusion theory (IDT). On this basis, the theory believes that key factors affecting use of new information technology are performance expectation, effort expectation, social influence and enabling factor. With the rapid development of modern information technology such as artificial intelligence, network and big data technology, accounting informatization has gradually changed to the direction of artificial intelligence, and accounting industry has stepped into the era of information technology. In application of artificial intelligence, accounting practitioners should gradually transform to management accounting, and individuals need to learn more knowledge and skills to become composite accounting talents. Therefore, accounting practitioners need to accept mobile learning to better adapt to social development and progress. They should constantly strengthen study of artificial intelligence, and accumulate experience, to equip themselves with conditions of new accounting talents. Based on the UTAUT model, this study adds two variables into the model, namely absorptive capacity and organizational commitment of accounting practitioners, to further enrich research content.

\subsection{Research hypothesis}

In this study, performance expectation refers to the fact that accounting practitioners' use of mobile learning will help improve their professional skills and level. For mobile education learners, performance expectation refers to the degree to which learners believe that mobile learning through use of mobile terminal devices will help them manage their daily life or improve their work performance interests and career development. Lin et al. [2] argued that in mobile learning, learners could be helped to manage daily life and study more effectively. It made their work better and helped them get reward or promotion at work. It would improve their behavior intention in mobile learning, and then they might produce actual behavior. Diep et al. [3] showed that performance expectation was the most important factor affecting adults' participation in online learning.

H1: Performance expectation has a significant positive impact on accounting practitioners' acceptance of mobile learning.

In this study, effort expectation refers to accounting practitioners' ease perception of information technology use. Ghalandari [4] studied the impact of effort expectation on acceptance of electronic banking services in Iran, and results showed that effort expectation had a positive impact on users' electronic banking service use. Sung et al. [5] conducted a questionnaire survey on 226 college students in Kyungnam Province, South Korea, and the study showed that effort expectation had a positive impact on performance expectation and willingness to use.

$\mathrm{H} 2$ : Effort expectation has a significant positive impact on accounting practitioners' acceptance of mobile learning.

In this study, social influence refers to the degree to which accounting practitioners believe that important people should use the system. Accounting practitioners' use of mobile learning is influenced by specific thoughts and behaviors of specific people or 
groups, thus affecting their use of mobile learning mode. Marsden et al. [6] reviewed empirical studies on social influence and pointed out several problems in norms, study design and measurement. Wood [7] believed that social relations should be embedded in analysis of attitudes and suggested that social identity theory should be used as basic theory.

H3: Social influence has a significant positive impact on accounting practitioners' acceptance of mobile learning.

Facilitating conditions in this study are the sum of convenient conditions and completeness of technical conditions that an accounting practitioner needs to use mobile learning platform to facilitate learning. In the existing UTAUT model, facilitating conditions on use intention has not been proved. Martins et al. [8] found that technical support was one of the key factors affecting effort expectation. McInerney [9] found that the academic atmosphere in facilitating conditions was positively correlated with students' academic performance.

H4: Facilitating conditions have a significant positive impact on accounting practitioners' acceptance of mobile learning.

In this study, absorption capacity refers to accounting practitioners as the crowd who has worked, besides some necessary knowledge of accounting, also need to have the ability to a new generation of information technology application, especially its application in the field of accounting, and the ability to use mobile learning ways to improve their comprehensive ability. Todorova et al. [10] suggested redefining the structure of absorptive capacity and believed that the dynamic model of absorptive capacity included feedback loop. Fosfuri et al. [11] found that absorptive capacity was the source of innovative competitive advantage of innovation-based enterprises, based on a sample survey of 2464 Spanish innovative enterprises. Yildiz et al. [12] paid attention to determinants of absorptive capacity at the individual level. Research showed that intrinsic motivation and overall capacity were the key causes of absorptive capacity, and employees with stronger absorptive capacity were more likely to accept multinational work. Lin [13] collected the data of 212 Taiwanese students, and research showed that absorption capacity could affect perceived usefulness and ease of use of ubiquitous learning.

H5: Absorptive capacity has a significant positive impact on accounting practitioners' acceptance of mobile learning.

In this study, organizational commitment refers to accounting practitioners' recognition and investment in their enterprises, and their willingness to participate in mobile learning to undertake various tasks and responsibilities to further improve their abilities and complete performance development. With the popularization of artificial intelligence technology, accounting practitioners in modern management system need to continue to teach performance management, capital market operation, risk control and other knowledge in the future development of accounting industry. Therefore, organizational commitment has a significant impact on their willingness to learn. Reichers [14] proposed measurement method of organizational commitment, which was more accurate and meaningful. D'Amato et al. [15] showed that organizational commitment resulted in differences in learning tendencies among people of different 
grades. Baotham et al. [16] found that teachers' job satisfaction had a significant positive impact on organizational commitment in all colleges and universities.

H6: Organizational commitment has a significant positive impact on accounting practitioners' acceptance of mobile learning.

\section{$3 \quad$ Methodology}

\subsection{Sample and data collection}

In this study, 7 variables including performance expectation, effort expectation, social impact, enabling conditions, organizational commitment, absorptive capacity and willingness to use were taken as potential variables, and basic information such as gender, professional type and educational level of the respondents were added to form a questionnaire on influencing factors of accounting practitioners accepting mobile learning. Considering the characteristics of the developed economy and accounting industry, this study selects small, medium and micro service enterprises in the Yangtze River Delta region of China, where the economy is relatively developed, to carry out research. Accounting employees in these regions have high overall literacy and have a good foundation to accept mobile learning. The specific research objects are chief financial officers, accounting department directors and front-line accounting personnel. The research period was from March to May, 2021. Electronic questionnaires were mainly sent out through QQ and WeChat. A total of 304 questionnaires were sent out and 265 were recovered with a recovery rate of $87.17 \%$. The 265 questionnaires were screened (filled in completely) and screened, and unqualified (inconsistent) and invalid questionnaires (all the answers were the same) were eliminated. A total of 215 valid questionnaires were obtained, with an effective rate of $81.13 \%$.

Table 1. Sample characteristics

\begin{tabular}{|l|c|c|c|}
\hline \multicolumn{1}{|c|}{ Classification } & Category & Number & Proportion \\
\hline \multirow{2}{*}{ Gender } & Male & 87 & $40.47 \%$ \\
\cline { 2 - 4 } & Female & 128 & $59.53 \%$ \\
\hline \multirow{2}{*}{ Position } & Front-line accounting Operator & 189 & $87.91 \%$ \\
\cline { 2 - 4 } & Accounting department directors & 21 & $9.77 \%$ \\
\cline { 2 - 4 } & Chief Financial Officer & 5 & $2.33 \%$ \\
\hline \multirow{2}{*}{ Whether the major is related to accounting } & Yes & 156 & $72.56 \%$ \\
\cline { 2 - 4 } & No & 59 & $27.44 \%$ \\
\hline \multirow{2}{*}{ Interactive friendliness of mobile learning platform } & Very friendly & 104 & $48.37 \%$ \\
\cline { 2 - 4 } & Relatively friendly & 76 & $35.35 \%$ \\
\cline { 2 - 4 } & Not very friendly & 35 & $16.28 \%$ \\
\hline
\end{tabular}




\subsection{Variable measurement}

The UTAUT model has been mature, including independent variables (performance expectation, effort expectation, social influence and facilitating conditions) and dependent variables (willingness to use). The measurement scale refers to quantitative design of existing questionnaires. Based on the existing UTAUT model, this study proposes that absorptive capacity and organizational commitment are two other factors that affect accounting practitioners' willingness to mobile learning. Absorptive capacity refers to the questionnaire of Minbaeva et al. (2003). Organizational commitment refers to the questionnaire of Cook et al. (2011). At the same time, considering particularity of accounting practitioners, Likert 5-level scale is used to measure, and to study the structure of influencing factors through quantitative means. The scale is divided into five levels: "strongly disagree", "disagree", "neutral", "agree" and "strongly agree" to measure the degree of approval of corresponding questions, and corresponding score from "strongly disagree" to "strongly agree" is assigned from one to five points.

\section{$4 \quad$ Result analysis}

\subsection{Reliability and validity test}

Reliability analysis is used to study accuracy of answers to quantitative data (especially attitude scale questions). Firstly, á coefficient is analyzed. If the value is higher than 0.8 , the reliability is high If this value is between $0.7-0.8$, it indicates that the reliability is good. If the value is between $0.6-0.7$, the reliability is acceptable. If this value is less than 0.6 , it indicates poor reliability. If the value of corrected item of total correlation (CITC value) is lower than 0.3, consider deleting the item. If the value of "á coefficient of the deleted item" is significantly higher than á coefficient, it can be considered to delete the item and re-analyze it.

As can be seen from Table 2, for "á coefficient of the deleted item" reliability coefficient does not increase significantly after any item is deleted. It indicates that item should not be deleted. The CITC values of analysis items are all greater than 0.4, indicating that there is a good correlation between analysis items, and it has a good reliability level. In summary, reliability coefficient value of research data is higher than 0.8 , which indicates that data reliability is of high quality and can be used for further analysis. The questionnaire and scale used in this survey are mature scales and scientifically and appropriately modified, so content validity test is not carried out. SPSS22.0 will be used for KMO and Bartlett sphericity test in this survey, and the results of the survey data are shown in Table 3.

Table 2. Cronbach's $\alpha$ coefficients

\begin{tabular}{|l|c|c|c|c|}
\hline \multicolumn{1}{|c|}{ Dimension } & $\begin{array}{c}\text { Question } \\
\text { number }\end{array}$ & $\begin{array}{c}\text { CITC } \\
\text { value }\end{array}$ & $\begin{array}{c}\boldsymbol{\alpha} \text { coefficient of the } \\
\text { deleted item }\end{array}$ & $\begin{array}{c}\text { Overall Cronbach's } \boldsymbol{\alpha} \\
\text { coefficient }\end{array}$ \\
\cline { 1 - 4 } Performance expectation & 3 & 0.674 & 0.830 & \multirow{2}{*}{0.794} \\
\hline Effort expectation & 4 & 0.551 & 0.846 & \\
\hline
\end{tabular}




\begin{tabular}{|l|l|l|l|}
\hline Social influence & 2 & 0.710 & 0.823 \\
\hline Facilitating conditions & 2 & 0.700 & 0.824 \\
\hline Organizational commitment & 2 & 0.487 & 0.854 \\
\hline Absorption capacity & 3 & 0.683 & 0.827 \\
\hline Willingness to use & 2 & 0.547 & 0.846 \\
\hline
\end{tabular}

Table 3. KMO and Bartlett tests

\begin{tabular}{|l|c|c|}
\hline \multicolumn{2}{|l|}{ KMO } & 0.860 \\
\hline \multirow{3}{*}{ Bartlett sphericity test } & The approximate chi-square & 579.494 \\
\cline { 2 - 3 } & Df & 21 \\
\cline { 2 - 3 } & P value & 0.000 \\
\hline
\end{tabular}

As can be seen from Table 3, KMO and Bartlett tests are used for validity verification. KMO value is 0.860 and it's greater than 0.8 , indicating very good validity of research data.

\subsection{Reliability and validity test}

AMOS22.0 is used to build the initial model, and the model is modified according to the fitting degree and modification index. The indexes of the revised model are shown in Table 4 and Table 5. The main reference indexes are all within the acceptable range, and the fitting effect of the model is good.

Table 4. Model fitting indexes

\begin{tabular}{|c|c|c|c|c|c|}
\hline GFI & RMSEA & RMR & CFI & NFI & IFI \\
\hline$>0.9$ & $<0.10$ & $<0.05$ & $>0.9$ & $>0.9$ & $>0.9$ \\
\hline 1.000 & 0.000 & 0.000 & 1.000 & 1.000 & 1.000 \\
\hline
\end{tabular}

Table 5. Covariance table

\begin{tabular}{|l|c|c|c|c|c|c|}
\hline $\mathbf{X}$ & $\mathbf{Y}$ & $\begin{array}{c}\text { Nonstandard estimation } \\
\text { coefficient } \\
\text { (Coef.) }\end{array}$ & $\begin{array}{c}\text { Standard error } \\
\text { (Std. Error) }\end{array}$ & $\mathbf{z}$ & $\mathbf{p}$ & $\begin{array}{c}\text { Standard estimation } \\
\text { coefficient } \\
\text { (Std. Estimate) }\end{array}$ \\
\hline $\mathrm{X}_{5}$ & $\mathrm{X}_{6}$ & 0.255 & 0.044 & 5.797 & 0.000 & 0.430 \\
\hline $\mathrm{X}_{4}$ & $\mathrm{X}_{6}$ & 0.384 & 0.055 & 6.963 & 0.000 & 0.540 \\
\hline $\mathrm{X}_{3}$ & $\mathrm{X}_{6}$ & 0.380 & 0.054 & 7.043 & 0.000 & 0.548 \\
\hline $\mathrm{X}_{2}$ & $\mathrm{X}_{6}$ & 0.247 & 0.042 & 5.869 & 0.000 & 0.437 \\
\hline $\mathrm{X}_{1}$ & $\mathrm{X}_{6}$ & 0.331 & 0.045 & 7.392 & 0.000 & 0.584 \\
\hline $\mathrm{X}_{4}$ & $\mathrm{X}_{5}$ & 0.274 & 0.046 & 5.958 & 0.000 & 0.445 \\
\hline $\mathrm{X}_{3}$ & $\mathrm{X}_{5}$ & 0.235 & 0.044 & 5.336 & 0.000 & 0.391 \\
\hline $\mathrm{X}_{2}$ & $\mathrm{X}_{5}$ & 0.099 & 0.034 & 2.908 & 0.004 & 0.202 \\
\hline $\mathrm{X}_{1}$ & $\mathrm{X}_{5}$ & 0.213 & 0.036 & 5.828 & 0.000 & 0.433 \\
\hline $\mathrm{X}_{3}$ & $\mathrm{X}_{4}$ & 0.478 & 0.059 & 8.079 & 0.000 & 0.660 \\
\hline $\mathrm{X}_{2}$ & $\mathrm{X}_{4}$ & 0.267 & 0.044 & 6.052 & 0.000 & 0.453 \\
\hline
\end{tabular}


Paper-Influencing Factors of Accounting Practitioners' Acceptance of Mobile Learning

\begin{tabular}{|l|l|l|l|l|l|l|}
\hline $\mathrm{X}_{1}$ & $\mathrm{X}_{4}$ & 0.282 & 0.045 & 6.314 & 0.000 & 0.477 \\
\hline $\mathrm{X}_{2}$ & $\mathrm{X}_{3}$ & 0.293 & 0.044 & 6.664 & 0.000 & 0.510 \\
\hline $\mathrm{X}_{1}$ & $\mathrm{X}_{3}$ & 0.346 & 0.046 & 7.549 & 0.000 & 0.601 \\
\hline $\mathrm{X}_{1}$ & $\mathrm{X}_{2}$ & 0.200 & 0.035 & 5.739 & 0.000 & 0.425 \\
\hline
\end{tabular}

Then, path test of the structural model is carried out, and on this basis, the hypothesis is tested. As shown in Table 6, the path coefficient value is estimated by the maximum likelihood method and it is found that 4 of the 6 hypotheses proposed are valid at the significance level of $5 \%$ and 2 are not.

Table 6. Regression coefficients of the model

\begin{tabular}{|c|c|c|c|c|c|c|c|}
\hline $\mathbf{X}$ & $\rightarrow$ & $\mathbf{Y}$ & $\begin{array}{c}\text { Nonstandardized path } \\
\text { coefficient }\end{array}$ & $\mathbf{S E}$ & $\begin{array}{c}\mathbf{z} \\
\text { (CR value) }\end{array}$ & $\mathbf{p}$ & Assuming conclusions \\
\hline $\mathrm{X} 1$ & $\rightarrow$ & $\mathrm{Y}$ & 0.181 & 0.078 & 2.308 & 0.021 & Accept the hypothesis \\
\hline $\mathrm{X} 2$ & $\rightarrow$ & $\mathrm{Y}$ & 0.242 & 0.069 & 3.51 & 0.000 & Accept the hypothesis \\
\hline $\mathrm{X} 3$ & $\rightarrow$ & $\mathrm{Y}$ & 0.203 & 0.065 & 3.143 & 0.002 & Accept the hypothesis \\
\hline $\mathrm{X} 4$ & $\rightarrow$ & $\mathrm{Y}$ & -0.11 & 0.071 & -1.56 & 0.119 & Refusing to hypotheses \\
\hline $\mathrm{X} 5$ & $\rightarrow$ & $\mathrm{Y}$ & 0.036 & 0.064 & 0.559 & 0.576 & Refusing to hypotheses \\
\hline $\mathrm{X} 6$ & $\rightarrow$ & $\mathrm{Y}$ & 0.15 & 0.064 & 2.335 & 0.020 & Accept the hypothesis \\
\hline
\end{tabular}

1. The study validates hypothesis H1. This conclusion is consistent with a large body of research. Performance expectation has positive influence on accounting practitioners' willingness to use mobile learning. Enterprises should choose to suit different quality of mobile learning platform, to strengthen construction of accounting related course content at the same time, and should set up different levels, different difficulties of learning content to improve accounting practitioners to the identity of the online learning. Because accounting practitioners generally use idle time to mobile learning, Enterprises can improve from aspects of content of the course design, course selection, namely, designing curriculum dominated by accounting practitioners, increasing independent inquiry, Q\&A, video and other forms, to let accounting practitioners think that mobile learning helps to promote knowledge learning. Only in this way can accounting practitioners' attitude towards mobile learning be influenced and their intention to use mobile learning is improved.

2. The study verifies hypothesis H2. Effort expectation positively affects accounting practitioners' willingness to use mobile learning. The vast majority of respondents in this questionnaire are young people with less than 5 years of working experience. They have good expectations for future development of their work. They can grasp the latest knowledge of accounting by strengthening their study, spending more time on study and strengthening their efforts. Therefore, various platforms of mobile learning should be designed around the object as the main body. Operation process should be simplified, and the platforms should have better interface guidance, and better compatibility. Then, accounting practitioners' understanding of the ease to use the mobile learning platform may be improved, and older accounting practitioners who accept mobile learning will also be attracted. 
3. The study validates hypothesis H3. Social influence positively affects accounting practitioners' willingness to use mobile learning. The main reason is that accounting is a relatively traditional industry, and mobile learning is a new thing. Especially after long-term accounting work, few will actively understand the use of mobile learning. The vast majority of accounting practitioners learn about the latest mobile learning platform through recommendation of relevant accounting personnel in the industry or enterprises and online advertising, so the social influence has become a key factor affecting users' willingness to use.

4. The study proves that hypothesis H4 is not valid. Facilitating conditions don't affect accounting practitioners' willingness to use mobile learning. When a new learning method of mobile learning is introduced, specialized mobile learning platforms or apps of accounting are not effective enough to provide learners with technical support. The failure to make learners believe that they can get technical help and support in mobile learning leads to reduction of actual behavior of accounting practitioners in mobile learning.

5. The study proves that hypothesis H5 is not valid. Organizational commitment doesn't affect accounting practitioners' willingness to use mobile learning. The main reason is that research object is accounting practitioners of small micro enterprises. They are more likely to come from China's private enterprises, and more accounting practitioners will focus on the money. They are lack of lifelong learning concept, mobile learning intention of enterprise arrangement or self-purchase related accounting course is not high.

6. The study validates hypothesis H6. In fact, the stronger the absorptive capacity of accounting practitioners is, the shorter the time to absorb new knowledge. It makes them be able to digest more new accounting knowledge in a shorter time range, and makes them easier to accept emerging learning way of mobile learning. Enterprises should introduce various incentive measures to stimulate learning enthusiasm of accounting practitioners and cultivate their absorptive ability, so that they can form concept of lifelong learning and internal dynamic mechanism of mobile learning at the same time. Mobile learning should increase proportion of practical courses for accounting practitioners [17-19]. While setting up the latest accounting theory knowledge, it should also enrich some contents with practical operation and interactive functions, and should use new education methods to improve their absorption ability of new knowledge.

\subsection{Analysis of variance}

In the research process, a large number of accounting practitioners attach interactive friendliness to mobile learning platform, which affects their willingness to use. This study continues to analyze whether interactive friendliness of mobile learning platform affects their willingness to use it by using variance analysis.

As it can be seen from Table 7, variance analysis shows that it presents a significant difference. Most accounting practitioners think the current Mobile learning platform is generally friendly to interaction. Various mobile learning platforms fail to effectively develop text materials, pictures, videos, audio and typical cases of ac- 
counting knowledge. Interactive friendliness affects accounting practitioners' willingness to use mobile learning platform.

Table 7. Equation analysis results

\begin{tabular}{|l|c|c|c|c|}
\hline \multicolumn{3}{|c|}{ Willingness to use (mean \pm standard deviation) } & \multirow{2}{*}{ F } & \multirow{2}{*}{ p } \\
\hline $1.0(\mathrm{n}=104)$ & $2.0(\mathrm{n}=76)$ & $3.0(\mathrm{n}=35)$ & & 0.000 \\
\hline $3.74 \pm 0.73$ & $4.20 \pm 0.41$ & $3.70 \pm 0.90$ & 12.229 & 0.900 \\
\hline
\end{tabular}

\section{Conclusion}

As an emerging open education learning form, mobile learning provides accounting practitioners with a more diversified learning environment and convenient and efficient learning experience. Based on the UTAUT model, this study conducts an empirical study on accounting practitioners' performance expectation, effort expectation, facilitating conditions, social influence, organizational commitment, absorptive capacity and other core factors of mobile learning. Results show that overall Cronbach's $\alpha$ coefficient of the questionnaire is 0.794 , with good reliability. The $\mathrm{KMO}$ value is 0.860 and the validity was very good. Performance expectation, effort expectation, social influence and absorptive capacity positively affect accounting practitioners' willingness to use of mobile learning. Results of univariate variance show that interactive friendliness of mobile learning platform has a significant impact on accounting practitioners' willingness to use. In the future, further research can be carried out on technology acceptance of specific mobile learning platforms, whether personal characteristics of different learners affect the willingness to accept, and whether interactive performance of mobile learning platforms and technology affect learning performance.

\section{Acknowledgment}

This study was supported by the National Cultural and Tourism Science and Technology Innovation Project, Henan Soft Science Research Project (212400410542), Henan Educational Science Project of 13th FiveYear Plan (2020yb0296), General Research Project of Humanities and Social Sciences in Colleges and universities of Henan Province (2022-ZZJH-282).

\section{$7 \quad$ References}

[1] Cook, J., Wall, T. (2011). New work attitude measures of trust, organizational commitment and personal need non-fulfilment. Journal of Occupational \& Organizational Psychology, 53(1): 39-52. https://doi.org/10.1111/j.2044-8325.1980.tb00005.x 
Paper-Influencing Factors of Accounting Practitioners' Acceptance of Mobile Learning

[2] Lin, C. P., Anol, B. (2008). Learning online social support: an investigation of network information technology based on UTAUT. CyberPsychology \& Behavior, 11(3): 268-272. https://doi.org/10.1089/cpb.2007.0057

[3] Diep, N. A., Cocquyt, C., Zhu, C., et al. (2016). Predicting adult learners' online participation: Effects of altruism, performance expectancy, and social capital. Computers \& Education, 101: 84-101. https://doi.org/10.1016/j.compedu.2016.06.002

[4] Ghalandari, K. (2012). The effect of performance expectancy, effort expectancy, social influence and facilitating conditions on acceptance of e-banking services in Iran: The moderating role of age and gender. Middle-East Journal of Scientific Research, 12(6): 801-807.

[5] Sung, H. N., Jeong, D. Y., Jeong, Y. S., et al. (2015). The relationship among self-efficacy, social influence, performance expectancy, effort expectancy, and behavioral intention in mobile learning service. International Journal of U-and E-Service, Science and Technology, 8(9): 197-206. https://doi.org/10.14257/ijunesst.2015.8.9.21

[6] Marsden, P. V., Friedkin, N. E. (1993). Network studies of social influence. Sociological Methods \& Research, 22(1), 127-151. https://doi.org/10.1177/0049124193022001006

[7] Wood, W. (2000). Attitude change: Persuasion and social influence. Annual review of psychology, 51(1): 539-570. https://doi.org/10.1146/annurev.psych.51.1.539

[8] Martins, L. L., Kellermanns, F. W. (2004). A model of business school students' acceptance of a web-based course management system. Academy of Management Learning \& Education, 3(1): 7-26. https://doi.org/10.5465/amle.2004.12436815

[9] McInerney, D. M. (2005). Facilitating conditions for school motivation: construct validity and applicability. Educational \& Psychological Measurement, 65(6): 1046-1066. https://doi.org/10.1177\%2F0013164405278561

[10] Todorova, G., Durisin, B. (2007). Absorptive capacity: Valuing a reconceptualization. Academy of management review, 32(3): 774-786. https://doi.org/10.5465/amr.2007.2527 $\underline{5513}$

[11] Fosfuri, A., Tribó, J. A. (2008). Exploring the antecedents of potential absorptive capacity and its impact on innovation performance. Omega, 36(2): 173-187. https://doi.org/10.1016 /j.omega.2006.06.012

[12] Yildiz, H. E., Murtic, A., Zander, U., et al. (2019). What fosters individual-level absorptive capacity in MNCs? An extended motivation-ability-opportunity framework. Management International Review, 59(1): 93-129. https://doi.org/10.1007/s11575-018-0367-x

[13] Lin, H. F. (2013). The effect of absorptive capacity perceptions on the context-aware ubiquitous learning acceptance. Campus-Wide Information Systems, 30(4): 249-265. https://doi.org/10.1108/CWIS-09-2012-0031

[14] Reichers, A. E. (1985). A review and reconceptualization of organizational commitment. Academy of management review, 10(3): 465-476. http://doi.org/10.2307/258128

[15] D'Amato, A., Herzfeldt, R. (2008). Learning orientation, organizational commitment and talent retention across generations. Journal of Managerial Psychology, 23(8): 929-953. http://doi.org/10.1108/02683940810904402

[16] Baotham, S., Sangsawang, T. (2010). The effects of job satisfaction on organizational commitment of thai employees in five rajabhat universities in the northern group. History of Education, 519(12): 78-84.

[17] Hariadi, B., Sunarto, M. J., Sagirani, T., Amelia, T., Lemantara, J., Prahani, B. K., Jatmiko, B. (2021). Higher order thinking skills for improved learning outcomes among indonesian students: A blended web mobile learning (BWML) model. International Journal of Interactive Mobile Technologies, 15(7): 4-16. https://doi.org/10.3991/ijim.v15i07. $\underline{17909}$ 
[18] Wachtler, J., Ebner, M. (2019). Scheduling interactions in learning videos: A state machine based algorithm. International Journal of Learning Analytics and Artificial Intelligence for Education, 1(1), 58-76. https://doi.org/10.3991/ijai.v1i1.10995

[19] Guralnick, D. (2020). From the international e-learning awards chair. International Journal of Advanced Corporate Learning, 13(3), 4. https://doi.org/10.3991/ijac.v13i3.18575

\section{Authors}

Guang Cheng is a doctoral candidate at Dongbei University of Finance and Economics, and is an associate professor at School of Accountancy, Henan University of Engineering, No.1, Xianghe Road, Longhu Town, Zhengzhou, China. His research interests focus on government accounting and accounting education.

Yige Shao is an accounting graduate student at Paul Merage School of Business, University of California-Irvine, 4293 Pereira Drive, Irvine, CA 92697, and has earned an undergraduate degree from Henan University of Engineering (Email: yiges4@uci.edu).

Article submitted 2021-11-30. Resubmitted 2022-01-05. Final acceptance 2022-01-06. Final version published as submitted by the authors. 